\title{
Breves comentários sobre o processo de democratização \\ das universidades públicas
}

\author{
Bernardo Parodi Svartman ${ }^{a}$ \\ José Leon Crochík \\ Gustavo Martineli Massola ${ }^{a}$ \\ aUniversidade de São Paulo, Instituto de Psicologia, Departamento de Psicologia Social e do Trabalho. São Paulo, SP, Brasil \\ 'Universidade de São Paulo, Instituto de Psicologia, Departamento de Psicologia da Aprendizagem, do Desenvolvimento \\ e da Personalidade. São Paulo, SP, Brasil
}

As recentes pressões para que as instituições públicas universitárias se transformem com o intuito de serem mais "produtivas", segundo os critérios cabíveis à mensuração da produção da forma geral mercadoria, têm sido objeto de intensos debates e reflexões. Já é possível encontrar abundante literatura discutindo o processo que propõe reduzir os objetivos das universidades à formação de técnicos acríticos e pesquisadores alinhados aos interesses do capital (Chauí, 2001; Leopoldo e Silva, 2014). De maneira geral, é possível observar que esse contexto mais amplo da economia em sua forma neoliberal e a consequente tendência de privatização dos serviços públicos determina a adoção desse tipo de racionalidade no interior mesmo das instituições universitárias, fazendo com que a organização do trabalho acadêmico se assemelhe em diversos aspectos àquela encontrada nas empresas privadas, com seus princípios de racionalização e avaliação da produtividade. No interior da universidade, essas transformações estão articuladas a uma reorganização da convivência política moldada para garantir sua efetividade, instaurando a competição como regra principal de convivência e uma estrutura de poder definida "por fortes mecanismos de controle e por fracos liames de representatividade, numa realização quase perfeita de democracia formal" (Leopoldo e Silva, 2014, p. 109). A crise de financiamento do ensino público universitário articula-se desta forma às mudanças de sua organização interna e de seu papel político, da relação dessa instituição com a totalidade social, levantando com isso a questão sobre o sentido da democratização dessas instituições.

Em um estimulante ensaio publicado no ano de 1959, Theodor Adorno apresentou uma análise sobre o processo de democratização das universidades alemãs (Adorno, 1959/2010). Levando-se em conta a enorme distância espaço-temporal entre o contexto analisado pelo autor e o atual momento brasileiro, ainda assim, o ensaio apresenta interessantes balizas de reflexão sobre os dilemas e contradições vividos contemporaneamente. Nesse texto, Adorno indicou que a expressão "democratização das universidades alemãs” possuía vários significados, todos interligados, e que uma reflexão rigorosa sobre o tema demandaria a tarefa de distingui-los e analisá-los em suas imbricações. $\mathrm{O}$ primeiro significado refere-se à questão do acesso à universidade, ou seja, se a possibilidade de ingresso e permanência se democratizou, se o acesso universal ao ensino superior está garantido. $\mathrm{O}$ segundo sentido está relacionado à pergunta de se as universidades "são democráticas em seu espírito e em sua estrutura interna" (Adorno, 1959/2010, p. 337). Por último, o sentido da expressão se liga à pergunta de se aqueles que saem da universidade "o fazem também com uma mentalidade democrática" (Adorno, 1959/2010, p. 337) e podem assim atuar de forma a difundir o espírito democrático na sociedade como um todo. As contradições ligadas às dificuldades da democratização da universidade nesses três âmbitos revelam as contradições mais amplas do conjunto da sociedade em seu desenvolvimento histórico.

Em relação ao primeiro significado, Adorno notava uma importante ampliação do acesso e das políticas de permanência estudantil nas universidades alemãs, embora apontasse também que a presença de filhos de trabalhadores era escassa, muito abaixo da porcentagem representada pela classe trabalhadora em relação à população total (Adorno, 1959/2010). Como um elemento provável, a necessidade imperiosa de se conseguir um trabalho dificultava a permanência dos filhos da classe trabalhadora na universidade. Esses problemas seguem evidentemente atuais e em nosso país ganham características específicas: eles se revelam na própria forma como as provas de ingresso nas universidades públicas operam mecanismos de exclusão e na dificuldade de consolidação de políticas adequadas de permanência estudantil para os que são oriundos das classes pobres. No entanto, é preciso levar em conta que o cenário em relação a este tema teve profundas mudanças nos últimos quinze anos, nos quais um conjunto de ações foi desenvolvido com o objetivo de enfrentar essa questão. Entre essas ações destacam-se a expansão de ofertas de vagas na rede pública, o sistema unificado de seleção, a implantação do programa PROUNI, a expansão do crédito estudantil e o desenvolvimento de ações afirmativas, como reserva de cotas para estudantes negros e reserva de vagas para estudantes oriundos das escolas públicas (Neves, Raizer, \& Fachinetto, 2007 p. 152). O conjunto dessas ações representa hoje um importante campo de pesquisas e debates que articula várias áreas do conhecimento, e muitas dessas pesquisas e análises se dedicam a avaliar seus efeitos e as contradições dessas ações, principalmente aquelas relacionadas à reprodução de desigualdades no conjunto do sistema (como as diferenças na qualidade da formação ofertada) e o fortalecimento da iniciativa privada na área da educação. 
A adoção das ações afirmativas enfrentou uma série de críticas de diferentes matizes políticas. Do lado de uma crítica que pode ser considerada conservadora, argumentou-se que os alunos não teriam condições de acompanhar os cursos e isso resultaria na diminuição da qualidade do ensino. Várias pesquisas recentes que compararam os rendimentos dos dois grupos de alunos indicam que não há diferenças substanciais no rendimento entre eles (Domingues, 2005; Velloso, 2009; Queiroz et al., 2015), indicando a falsidade desses argumentos. De um lado que poderia ser considerado mais progressista, também é possível perceber um campo de debate entre posições divergentes. Autores que adotam uma orientação marxista argumentam que as ações afirmativas carregam o risco de configurar uma política reformista que deixa intacta a estrutura injusta da seleção pelo vestibular e que pode incorrer em uma fragmentação da luta da classe trabalhadora (Leite, 2011). As posições que argumentam a favor da adoção das cotas e reservas de vaga não questionam seu caráter até certo ponto reformista, mas enfatizam seu caráter democratizante e a necessidade da imediata reparação das injustiças e opressões relacionadas à histórica e presente discriminação étnico-racial no Brasil (Domingues, 2005, p. 168), possibilitando com isso a preparação de alterações mais profundas e estruturais. Ainda que esta política afirmativa tenha conseguido importantes resultados no processo de democratização do acesso ao ensino superior, parece um consenso que as políticas de permanência estudantil demandariam maior investimento, e que esta necessidade se encontra hoje ainda mais ameaçada em função da crise de financiamento vivida pelas universidades públicas. É possível que da tensão entre os argumentos presentes neste campo mais progressista, favorável efetivamente à democratização do acesso ao ensino superior, possa surgir um projeto articulador de ações de curto, médio e longo prazo, aliando a necessidade de mudanças imediatas a um projeto que torne possível um horizonte de acesso universal ao ensino público de qualidade (incluindo políticas adequadas de permanência estudantil em todos os níveis). Países onde este tipo de acesso está garantido poderiam servir de inspiração, sem deixarmos de levar em conta a existência de mecanismos de exclusão operando ao longo das etapas anteriores de formação mesmo nesses contextos de acesso universal à universidade pública.

Em relação ao segundo significado, o de se as universidades "são democráticas em seu espirito e estrutura interna", é possível observar as enormes dificuldades encontradas por algumas instituições públicas em alcançar formas de convivência e de governança democrática. Como apontou a Associação de Docentes da Universidade de São Paulo em um documento que apresenta propostas para a democratização dessa universidade, no ano de 2013, 66,39\% dos professores que compõem o Conselho Universitário eram professores titulares, embora esse grupo represente $17,71 \%$ do corpo docente dessa universidade (Adusp, 2015). A categoria de professores doutores, embora represente $50,56 \%$ do corpo docente, tinha direito a três dos 122 assentos existentes no conselho. Essas distorções de representação no Conselho Universitário também estão presentes nas categorias dos funcionários técnicos-administrativos e na categoria discente (Adusp, 2015). As eleições diretas e paritárias para cargos importantes da gestão universitária também não estão incorporadas em seu estatuto, dificultando o debate sobre os programas e projetos das gestões entre a comunidade acadêmica. Esses dados revelam apenas um aspecto de um conjunto amplo de dificuldades relacionadas à governança das instituições de ensino superior, como aponta ainda esse documento produzido pela Associação de Docentes da Universidade de São Paulo: dificuldades de participação da comunidade universitária no planejamento e no acompanhamento da execução orçamentária e formas de avaliação de desempenho impostas sem negociação interna, são alguns dos elementos que agravam esse processo de impedimento de formação de um verdadeiro espírito de convivência democrática dentro das universidades. É possível imaginar que muitas instituições de ensino superior compartilhem em maior ou menor medida alguns dos elementos agrupados nesse documento apresentado pela Adusp. A amplitude de questões relacionadas a esse problema permite pensar que a democratização interna das universidades não se restringe à representatividade formal em número equitativo das diversas categorias, ainda que isso seja importante; refere-se também às formas de reconhecimento do trabalho de pesquisadores - docentes, funcionários e alunos - que não visem somente a produtividade imediata, mas apoiem o desenvolvimento de pesquisas básicas ou de pesquisas que não tenham relação imediata com as necessidades sociais atuais ou com demandas próprias dos setores privados da produção. Uma vez que a sociedade se modifica ao longo do tempo, suas necessidades também se modificam, e as pesquisas e a formação de profissionais devem prepará-los para as modificações sociais e para que sejam capazes de refletir sobre o caráter dessas mudanças no que implicam de avanço ou retrocesso social; em uma sociedade violenta como a nossa, a educação deve ser necessariamente política (ver Adorno, 1967/1995), ainda que não imediatamente engajada. $\mathrm{O}$ pesquisador deve ter autonomia e liberdade para pensar para além da utilidade imediata ou do ativismo político sem perspectiva temporal; esse ponto certamente se relaciona diretamente com o último sentido assinalado por Adorno, em seu texto sobre a presença da democracia nas universidades alemãs, que será pensado a seguir.

$\mathrm{O}$ aspecto mais interessante da exposição e que se relaciona diretamente à questão da formação universitária e da produção e publicação científica na atualidade, é que, segundo o autor, não devemos supor que alguns avanços constatados na direção da democratização das universidades (detectados pelo autor no contexto alemão do período em que o texto foi redigido) correspondam diretamente a um verdadeiro processo de democratização da consciência dos indivíduos (Adorno, 1959/2010). A possibilidade de oposição do espírito frente ao existente, frente às condições em que se deve encontrar um trabalho, se debilita na 
mesma medida em que cresce o poder destas condições, resultando igualmente na diminuição da autonomia dos indivíduos. Nesse contexto de fortalecimento do poder que condiciona a organização social do trabalho, principalmente em sua forma monopolista, a educação e a pesquisa tendem a diminuir seu potencial crítico, limitando-se a preparar os alunos para aceitação e aprimoramento do já existente. A partir disso, Adorno pode notar uma contradição importante no espirito da própria formação universitária:

Justamente esse tipo de homem livre, que é capaz de determinar-se a si mesmo porque sabe que de sua autodeterminação depende a do todo, se encontra em declive nas universidades simplesmente porque a sociedade faz tempo não o honra como acaso o fazia nos começos da era do liberalismo. Mas isto faz com que os sujeitos para os que, contudo, está pensada uma democracia em seu verdadeiro sentido respondam cada vez menos ao que a ideia de democracia exige. Existe então a possibilidade de que o processo de democratização dentro da universidade entre em conflito com o espírito da democracia porque o espírito que este processo produz, ou ao menos reproduz, não é verdadeiramente democrático. Esta possibilidade deve ser levada em conta, sem ilusão, por quem não se contente com progressos de fachada. (Adorno, 1959/2010, pp. 340-341, tradução nossa)

Sobre esta contradição já constatada por Adorno no final da década de 1950, muito poderia ser dito sobre seu desenvolvimento nas atuais formas de ensino e pesquisa. Ao discutir as principais tendências da pesquisa social empírica de sua época, Adorno pode elogiar o desenvolvimento de instrumentos e pesquisas capazes de oferecer dados confiáveis e importantes sobre a sociedade, e ao mesmo tempo enfatizar que o próprio desenvolvimento dessa racionalidade científica, que se aproximava cada vez mais dos modelos das ciências naturais, resultava em obstáculo à observação dos momentos objetivos da totalidade social que fazem a mediação do que é observado (Adorno, 2001), restringindo o próprio sentido e relevância da pesquisa. Esse fenômeno contraditório também se torna notável no campo da psicologia: a própria racionalidade das pesquisas empíricas segundo o modelo dominante dificulta a observação dos momentos objetivos implicados na formação de seu objeto, e com isso também se tornam incapazes de apreender seu movimento histórico. Em parte considerável das pesquisas empíricas, a teoria, quando comparece, o faz de forma cada vez mais formal, sem uma relação interna com o próprio objeto pesquisado. Seja pela afirmação de uma relação direta e sem mediações entre indivíduo e sociedade, ou pela desconsideração dos momentos objetivos relacionados com sua formação, impede-se a formulação crítica do próprio estranhamento mútuo presente nessa relação. Esta é uma das formas pelas quais se prepara a aceitação do presente em nosso campo e se impede a compreensão da indiferença da totalidade social para o que é especifico. Quando as pesquisas reproduzem o estranhamento simplesmente confirmando-o, comprometem a atuação democrática, que não pode prescindir de uma análise das forças sociais existentes para se posicionar de forma que o conflito não resulte em continua e fatídica opressão. Este processo em seu conjunto também diminui a possibilidade de elaboração crítica das experiências atuais de individuação, diminuindo igualmente o campo de análise das contradições que permitiriam transformações relacionadas ao fortalecimento do indivíduo e à promoção da autonomia e felicidade humana.

Como já apontava Adorno (1959/2010) nesse ensaio, essa contradição não pode ser enfrentada de forma voluntarista, como se fosse apenas uma dificuldade interna à universidade, já que provém da sociedade como um todo. No entanto, a tarefa que se impõe a partir dessa constatação não é a busca e a retomada de antigos padrões de formação, e sim a busca por uma atividade incessante de reflexão sobre as condições que produzem essa contradição entre um processo de democratização formal das instituições e a diminuição da consciência democrática, com o objetivo de avaliar o que poderíamos mudar nessas condições (Adorno, 1959/2010). Além disso, essa constatação, quando verdadeiramente elaborada e incorporada pelo corpo docente, tem importantes implicações sobre sua atuação e sobre o processo de formação universitária: a busca incessante para que a formação pudesse reforçar a autoconsciência crítica dos alunos, capaz de permitir a defesa contra a propaganda e a coação.

\section{Referências}

Adorno, T. W. (1995). Educação após Auschwitz. In Educação e emancipação (pp. 119-138). Rio de Janeiro, RJ: Paz e Terra. (Trabalho original publicado em 1967)

Adorno, T. W. (2001). Sociología e investigación empírica. In Epistemología y Ciencias Sociales (pp. 19-36). Madrid: Cátedra. (Trabalho original publicado em 1957)

Adorno, T. W. (2010). La democratización de las universidades alemanas. In Miscelánea I: obra completa (pp. 337-342). Madrid: Akal. (Trabalho original publicado em 1959)

Adusp (2015). Propostas da ADUSP para democratizar a Universidade de São Paulo (USP). Texto disponível no link: http://www.adusp.org.br/files/cadernos/ democracia.pdf

Chauí, M. (2001). Escritos sobre a universidade. São Paulo, SP: Unesp. 
Domingues, P. (2005). Ações afirmativas para negros no Brasil: o início de uma reparação histórica. Revista Brasileira de Educação, 29, 164-177.

Leite, J. L. (2011). Política de cotas no Brasil: política social? Revista Katálysis, 14(1), 23-31.

Leopoldo e Silva, F. (2014). Universidade, cidade, cidadania (Valter José, org.). São Paulo, SP: Hedra.

Queiroz, Z. C. L. S., Miranda, G. J., Tavares, M., \& Freitas, S. C. (2015). A lei de cotas na perspectiva do desempenho acadêmico na Universidade Federal de Uberlândia. Revista Brasileira de Estudos Pedagógicos, 96(243), 299-320.

Neves, C. E. B., Raizer, L., \& Fachinetto, R. F. (2007). Acesso, expansão e equidade na educação superior: novos desafios para a política educacional brasileira. Sociologias, 9(17), 124-157.

Velloso, J. (2009). Cotistas e não-cotistas: rendimento de alunos da Universidade de Brasília. Cadernos de Pesquisa, 39(137), 621-644. 